\title{
Mucocutaneous warts in Middle Anatolia, Turkey: clinical presentations and therapeutic approaches
}

\author{
'Department of Dermatology, Dıskapı Research and Training Hospital, Ankara, Turkey \\ Head of the Department: Assist. Prof. Müzeyyen Gönül \\ ${ }^{2}$ Department of Dermatology, Yenimahalle State Hospital, Ankara, Turkey \\ ${ }^{3}$ Department of Dermatology, Ağrı State Hospital, Ağrı, Turkey \\ ${ }^{4}$ Dermatology Department, School of Medicine, Balikesir University, Balikesir, Turkey \\ ${ }^{5}$ Department of Dermatology, Numune Research and Training Hospital, Ankara, Turkey \\ Head of the Department: Prof. Dr. Ülker Gül \\ ${ }^{6}$ Family Medicine, Kilis Public Health Research, Kilis, Turkey
}

Müzeyyen Gönül' ${ }^{1}$ Emine Unal², Ayşegül Yalçınkaya lyidal ${ }^{3}$, Seray Çakmak ${ }^{4}$, Arzu Kılıç4, Ulker Gul', Pinar Doner ${ }^{6}$

Postep Derm Alergol 2015; XXXII (3): 179-183

DOI: $10.5114 /$ pdia.2015.48054

\begin{abstract}
Introduction: Viral warts are common skin condition caused by the human papilloma virus.

Aim: To determine the clinical features of warts and therapeutic approaches to warts and compare them with the literature.

Material and methods: A cross-sectional survey was conducted on 362 consecutive patients presenting to a dermatology clinic in Ankara, Middle Anatolia, Turkey. Age, gender, anatomic localization, clinical types, number of warts, and medical therapy histories were recorded.

Results: In our study 139 (38.4\%) children and 223 (61.6\%) adults had warts. Warts were seen in 191 men, and 171 women. The mean age was $24.7 \pm 13.5$. In all groups the incidence and the number of warts were higher in men. Clinical types of warts were vulgar, anogenital, plantar, verruca plana, filiform, and mosaic. Thirty-six (9.9\%) of 362 cases had more than one type. The locations of warts were as follows extremities ( $n=233,64.4 \%)$, anogenital $(n=86,23.7 \%)$ and head and neck ( $n=73,20.2 \%)$. The incidence of anogenital warts was statistically higher in men than women $(p<0.05)$. Topical medical treatment was the first choice $(n=60,57.1 \%)$.

Conclusions: In our study, the incidence and the number of warts were higher in men, which is different than in previous reports. The anogenital wart (AW) was ranked second in all types of warts. According to this finding, we can say that the frequency of AW has been increased in Turkey. To our knowledge recently there have been no studies investigating the clinical features of viral warts in all ages in the literature.
\end{abstract}

Key words: common wart, anogenital wart.

\section{Introduction}

Viral warts are common skin conditions caused by the human papilloma virus (HPV). Most people will experience warts at some time of their life. HPV can be associated with a variety of cutaneous and mucosal manifestations [1-3].

\section{Aim}

In this study, we aimed to investigate the clinical features of patients with viral warts, to determine what medications the dermatologists prefer to treat warts in our region and compare them with the literature.

\section{Material and methods}

A cross-sectional survey was conducted on 362 consecutive patients presenting to a dermatology outpatient clinic in Ankara, Middle Anatolia, Turkey. The approval for the study was received from the Ankara Numune Education and Research Hospital Scientific Committee.

Address for correspondence: Emine Unal, Department of Dermatology, Yenimahalle State Hospital, Ankara, Turkey, phone: 05309334337, fax: 03122553775, e-mail: eminesu83@gmail.com Received: 21.02.2014, accepted: 11.09.2014. 
Dermatological examinations of the patients were made and age, gender, anatomic localization, clinical types and number of warts, medical therapy history, and family history for warts were recorded. The classification of warts was based on morphology and anatomic localization. Demographic features of children and adults with warts were determined. Patients $\leq 18$ years old were included in the children group. Patients who had anogenital warts were divided into 3 age groups: $\leq 18$ years old, $19-45$ years old, and $>45$ years old.

We recorded anatomic localization, type of warts, number of warts and median wart number in all patients and compared them between children and adults.

\section{Statistical analysis}

Data analysis was performed by using SPSS for Windows, version 11.5 (SPSS Inc., Chicago, IL, United States). Metric discrete variables were shown as mean \pm standard deviation (SD) or median (min-max), where applicable. Nominal data were expressed as the number of cases and percentages. Whether the differences in the median number of warts between groups were statistically significant or not was evaluated by Mann Whitney $U$ test. Nominal data were analyzed by Pearson's $\chi^{2}$ or Fisher's exact test, where appropriate. Multiple Logistic Regression analysis was applied for determining the best predictors which have an effect on the number of warts, after adjustment for all possible risk factors. Odds ratios and $95 \%$ confidence intervals for each independent variable were also calculated. A $p$ value less than 0.05 was considered statistically significant.

\section{Results}

Warts were more frequently seen in men; in adult men and girls in children. Hands, particularly periungal areas, were the most involved areas. The most frequent type was vulgaris followed by anogenital wart (AW) There were no differences in the localization of warts according to gender in children but in adults warts were more frequent on hands and soles in females. In our study, AW ranked second in all types of warts. According to this finding, we can say that the frequency of AW has been increased.

Table 1. Clinical types of warts in children and adults

\begin{tabular}{lccc}
\hline Type & $\begin{array}{c}\text { Children } \\
(N=139) \\
n(\%)\end{array}$ & $\begin{array}{c}\text { Adult } \\
(N=223) \\
n(\%)\end{array}$ & Value of $p$ \\
\hline Vulgar & $93(66.9)$ & $188(84.3)$ & $<0.001$ \\
\hline Plantar & $32(23.0)$ & $36(16.1)$ & 0.103 \\
\hline Plana & $17(12.2)$ & $8(3.6)$ & 0.002 \\
\hline Filiform & $13(9.4)$ & $4(1.8)$ & $<0.001$ \\
\hline Mosaic & $4(2.9)$ & $4(1.8)$ & 0.489 \\
\hline
\end{tabular}

\section{Discussion}

The HPVs are small DNA viruses of the papovavirus family. The HPVs are among the most common infectious agents in humans. Warts have usually been diagnosed by clinical examination. Warts are spread by contact from person to person or from environment. The worldwide prevalence of viral warts differs from region to region [1-5].

Prevalence of warts in adults was reported to be $3.5 \%$ and up to $33 \%$ in primary schoolchildren [2]. A survey of 6300 pediatric dermatology patients in Ankara, Turkey in 2004-2006 had shown viral warts to be the fourth most prevalent dermatosis (9.5\%) [6]. In another study conducted in the Göller region, south Turkey, in 1994-1996 in 10,100 cases of dermatological diseases (both children and adults), verruca vulgaris frequency was $2.9 \%$ [7]. We could not determine the frequency of warts among all dermatological diseases because we could not exclude recurrent application of patients through the hospital information system. In this study we aimed to investigate clinical features of warts nowadays rather than the frequency of warts. There are few articles about this subject in the literature $[4,8,9]$ and there is no available study in Turkey.

Most of the studies in the literature classified the types of warts as common (vulgar), plana, plantar and anogenital [4, 8, 9]. We classify warts as vulgar, plane, plantar, filiform, mosaic and anogenital. The most frequent type was verruca vulgaris (77.6\%) similarly as in the literature [1-4] and followed by AW (23.7\%), plantar (18.8\%), verruca plana (6.9\%), filiform (4.7\%), and mosaic (2.2\%). In our country Baysal et al. had reported that the most frequent type of warts was the vulgar type and was followed by plantar, plana, and anogenital types [7]. But in our study AW was the second most frequent type. Baysal et al. had conducted this study in the Mediterranean region of Turkey 17 years ago. In the recent years changes in sexual life (sexual freedom, different sexual habits, increase in the number of partners) might have caused this discrepancy. Also it might be related to regional differences. Ozgul et al. reported a study which showed the prevalence of genital warts nationwide in Turkey. They collected data from gynecologists from different regions. The highest prevalence had been observed in the Western part of Turkey in the Aegean region followed by Middle-Anatolia [10]. In our study, vulgar and anogenital types were significantly higher in adults, while plane and filiform types were higher in children $(p<0.05)$, which is similar to the literature (Table 1) [2, 3]. 9.9\% of cases had more than one type of warts. The prevalence of the multiple type of warts was statistically higher in men ( $p=0.029)$ similarly as in the literature [4].

HPV infection is seen commonly in children with the peak incidence occurring between 12 and 16 years [5]. In our study, the mean age was $11.9 \pm 4.3$ years in children which is nearly similar to the literature. Demographic 
Table 2. Demographic features of children and adults with warts

\begin{tabular}{lcc}
\hline Parameter & Children $(N=139)$ & Adult $(N=223)$ \\
\hline Age & $11.9 \pm 4.3$ & $32.7 \pm 10.9$ \\
\hline Gender, $n(\%):$ & & \\
\hline Male & $63(45.3)$ & $128(57.4)$ \\
\hline Female & $76(54.7)$ & $95(42.6)$ \\
\hline
\end{tabular}

features of all of the patients are shown in Table 2. Anogenital wart was more common in adults than children; extremity and head-neck localizations were more common in children than adults. These results were similar to the literature $[1,2]$.

In the literature the differences in the gender of patients with warts are controversial. In our study in all age groups the incidence of warts were higher in males $(p<0.05)$. When analyzing the children group, the frequency of warts was higher in girls in our study. In the literature, while some authors suggested there were no differences in the gender of the patients, Al-Mutairi and Theng et al. reported that boys were more affected than girls [4, 9]. We could not reach any information whether warts show any gender difference in adults or not as most of the available studies had been conducted in children groups. As well as one of the results of our study shows that men were more affected than women. The most frequent localization of the body was hands, which is similar to the literature [1-5]. Warts were statistically more frequent on hands and head-neck in children than adults $(p<0.05)$. This might be beacuse children have more physical activity than adults, so they could injure themselves and bite their nails more than adults and contamination could occur from hands to their head-necks. In adults, also the most frequent localization was hands, which is similar to the literature [1-5]. Comparing the frequency of skin site involvements between genders in the adult group, we found hand and sole involvement to be higher in females $(p<0.001)$. This result could be because of housework. Doing housework causes a tendency to abrasion and breaks the skin and viruses easily pass from damaged skin. Females more frequently do housework so they have abrasions and breaks in their skin more than males. There were no differences according to the localization between boys and girls. Al-Mutairi et al. and Theng et al. had reported that hand involvement tended to be higher in boys because boys are more active physically. We did not find any differences like Theng et al. and Al-Mutairi et al. [4, 9]. Hands were the most affected area of the body and periungal area was the most affected part of the hand, similarly to the literature [1, 2, 5]. We thought that because of trauma, the incidence of warts could be higher in the dominant hand. But there were no differences between the right
Table 3. Sites of involvement of warts in children and adults

\begin{tabular}{lccc}
\hline Site & $\begin{array}{c}\text { Children } \\
(N=139) \\
n(\%)\end{array}$ & $\begin{array}{c}\text { Adults } \\
(N=223) \\
n(\%)\end{array}$ & Value of $p$ \\
\hline Hand & $79(56.8)$ & $89(39.9)$ & 0.002 \\
\hline Sole & $31(22.3)$ & $36(16.1)$ & 0.142 \\
\hline Extremity & $108(77.7)$ & $125(56.1)$ & $<0.001$ \\
\hline Anal & $3(2.2)$ & $14(6.3)$ & 0.072 \\
\hline Genital & $1(0.7)$ & $76(34.1)$ & $<0.001$ \\
\hline Head-neck & $44(31.7)$ & $29(13.0)$ & $<0.001$ \\
\hline
\end{tabular}

and left hand. We did not find a report that compared the left and right hand in the literature. The trunk is less affected compared to other sites of the body in all groups similarly to Theng et al. [9]. This may be because trauma and contact with the virus is less in this region of the body (sites of involvement of warts in children and adults are shown in Table 3 and detailed localization of warts for children and adults is shown in Table 4).

In our study, the mean number of warts was 7.03 \pm 8.08 (6.5 \pm 7.8 in children, $7.3 \pm 8.2$ in adults). Al-Mutairi and Alkhalaf presented that the mean number of warts in children was 5.6, which is near to our study but they did not compare the girls and boys [4]. The median number of warts was 4 in our study; 4 in children and 5 in adults. There were no differences between children and adults in the median number of warts. In children, the median number was similar between girls and boys but in adults it was statistically higher in men than women ( $p<0.001)$. This is because AW was higher in adult men than women $(p=0.029)$ and patients with AW present with a high number of warts.

In our study, 111 (30\%) of 361 cases had family history of warts and in the study that had been presented by Al-Mutairi and Alkhalaf [4], the rate was 19.8\%. There were no differences in the median number of warts who had a family history of warts.

Anogenital wart was seen in $86(23.7 \%)$ of 362 cases. Seventy cases (81.4\%) were in 19-45-year-old group and only 4 (4.7\%) were cases in $\leq 18$-year-old group. Anogenital warts were statistically higher in men than women in our study as in the literature from Turkey $(p<0.05)$ $[11,12]$. None of them had a history of application of HPV vaccination. This may be due to that males usually have more partners than females and they have more risk to have an infection compared to women.

Anogenital wart in children could be associated with sexual abuse but it is not a rule. Some reports suggested that AW could be transmitted by hand-genital contact. This transmission could be by autoinoculation from one site of the body to another, hetero-inoculation from oth- 
Table 4. Detailed localization of warts for children and adults

\begin{tabular}{|c|c|c|c|c|c|c|}
\hline \multirow[t]{2}{*}{ Localization } & \multicolumn{3}{|c|}{ Children } & \multicolumn{3}{|c|}{ Adults } \\
\hline & $\begin{array}{c}\text { Boy } \\
(N=63) \\
n(\%)\end{array}$ & $\begin{array}{c}\text { Girl } \\
(N=76) \\
n(\%)\end{array}$ & Value of $p$ & $\begin{array}{c}\text { Male } \\
(N=128) \\
n(\%)\end{array}$ & $\begin{array}{c}\text { Female } \\
(N=95) \\
n(\%)\end{array}$ & Value of $p$ \\
\hline Leg & $0(0.0)$ & $1(1.3)$ & 1.000 & $0(0.0)$ & $2(2.1)$ & 0.180 \\
\hline Arm & $1(1.6)$ & $1(1.3)$ & 1.000 & $2(1.6)$ & $3(3.2)$ & 0.653 \\
\hline Hand & $36(57.1)$ & $43(56.6)$ & 1.000 & $39(30.5)$ & $50(52.6)$ & $<0.001$ \\
\hline Sole & $14(22.2)$ & $17(22.4)$ & 0.984 & $9(7.0)$ & $27(28.4)$ & $<0.001$ \\
\hline Dorsa of foot & $2(3.2)$ & $3(3.9)$ & 1.000 & $3(2.3)$ & $6(6.3)$ & 0.175 \\
\hline Trunk & $2(3.2)$ & $0(0.0)$ & 0.204 & - & - & - \\
\hline Anal & $0(0.0)$ & $3(3.9)$ & 0.251 & $6(4.7)$ & $8(8.4)$ & 0.256 \\
\hline Genital & $1(1.6)$ & $0(0.0)$ & 0.453 & $67(52.3)$ & $9(9.5)$ & $<0.001$ \\
\hline Scalp & $5(7.9)$ & $1(1.3)$ & 0.091 & $2(1.6)$ & $0(0.0)$ & 0.509 \\
\hline Chin & $2(3.2)$ & $5(6.6)$ & 0.456 & $1(0.8)$ & $1(1.1)$ & 1.000 \\
\hline Cheek & $5(7.9)$ & $8(10.5)$ & 0.602 & $1(0.8)$ & $6(6.3)$ & 0.044 \\
\hline Forehead & $2(3.2)$ & $7(9.2)$ & 0.183 & $3(2.3)$ & $2(2.1)$ & 1.000 \\
\hline Nose & $1(1.6)$ & $5(6.6)$ & 0.221 & $2(1.6)$ & $4(4.2)$ & 0.405 \\
\hline Lips & $6(9.5)$ & $5(6.6)$ & 0.546 & $2(1.6)$ & $3(3.2)$ & 0.653 \\
\hline Eyelid & $2(3.2)$ & $4(5.3)$ & 0.689 & $0(0.0)$ & $1(1.1)$ & 0.426 \\
\hline Neck & $0(0.0)$ & $1(1.3)$ & 1.000 & $5(3.9)$ & $0(0.0)$ & 0.073 \\
\hline Nose mucosa & $1(1.6)$ & $1(1.3)$ & 1.000 & $0(0.0)$ & 1 (1.1) & 0.426 \\
\hline Oral mucosa & 1 (1.6) & $0(0.0)$ & 0.453 & $1(0.8)$ & $1(1.1)$ & 1.000 \\
\hline
\end{tabular}

er family members, and indirect transmission, and some of them may not be caused by genital types of HPV [1315]. In our study, only 5 (5.8\%) cases (2 of them were children, 3 of them were adults) had warts both on hands and the anogenital region. Four (2.8\%) (3 girls and 1 boy) of 139 children had AW. The rate was low in our study when comparing to the study reported by Al-Mutairi and Alkhalaf (5.83\%) [4]. Girls were 4-14-years old and had warts in their anal region. Two of them had family history and the other girl had a wart on her hands. Only 1 child was a boy and had a wart in the genital region.

Table 5. Therapy history of the patients $(N=105)$

\begin{tabular}{lc}
\hline Therapy history & $\boldsymbol{N}(\%)$ \\
\hline Topical treatments & $60(57.1)$ \\
\hline Cryotherapy & $40(38.1)$ \\
\hline Electrocautery & $11(10.5)$ \\
\hline Levamisol & $3(2.9)$ \\
\hline Spiritual healing & $2(1.9)$ \\
\hline
\end{tabular}

He was 18 years old and had no family history. It was difficult to say how the children had been infected with HPV. Girls might have been infected by their family or autoinoculation and the boy might have been infected sexually because he was in a sexually active age. We could not identify HPV types because of the limits of our laboratory.

There is no only single treatment for warts, usually different types of treatment may be combined. Treatment should be simple and the therapy which has the minimal risk of adverse effects should be chosen [16-18]. In this study, we aimed to know what medications the dermatologists preferred to treat warts in our region. We recorded therapy history. We did not follow up the therapy response to warts. There was a wide range of treatments. Some of the patients had used several medications. Topical treatments were the first choice in all types (Table 5), which is similar to the literature $[16,17,19]$. Topical treatments that had been used were salicylic acid, lactic acid, 5-fluorouracil and retinoic acid for non-genital cutaneous warts and podophyllin and imiquimod for AW. In verruca vulgaris and plantaris, 
cryotherapy was the second chosen therapy as offered in the literature $[16,17,19]$.

Several treatment options are available for AW in adults. Spontaneous resolution of pediatric AW is high and because of this cases may be followed up without any treatment. Topical agents such as podophyllin, imiquimod or ablation with cryotherapy, laser therapy or excision should be considered [16]. In our study, cryotherapy (15.1\%) was the first choice in AW. But in the world, the first choice was topical treatments [17, 20, 21].

\section{Conclusions}

Further studies will show the discrepancies of clinical features between different countries and/or geographic and socioeconomic regions.

\section{Acknowledgments}

The study was conducted at the Numune Research and Training Hospital, Department of Dermatology, Ankara, Turkey.

\section{Conflict of interest}

The authors declare no conflict of interest.

\section{References}

1. Sterling JC, Handfield-Jones S, Hudson PM. Guidelines for the management of cutaneous warts. Br I Dermatol 2001; 144: 4-11.

2. Cardoso JC, Calonje E. Cutaneous manifestations of human papillomaviruses: a review. Acta Dermatovenerol Alp Pannonica Adriat 2011; 20: 145-54.

3. Karadag AS, Balta I. Human pailloma viruses and skin. Turkiye Klinikleri J Dermatol-Special Topics 2013; 6: 47-57.

4. Al-Mutairi N, Alkhalaf M. Mucocutaneous warts in children: clinical presentations, risk factors, and response to treatment. Acta Dermatovenerol Alp Pannonica Adriat 2012; 21: 69-72.

5. Herman BE, Corneli HM. A practical approach to warts in the emergency department. Pediatr Emerg Care 2008; 24: 246-51.

6. Tamer E, Ilhan MN, Polat M, et al. Prevalence of skin diseases among pediatric patients in Turkey. J Dermatol 2008; 35: 413-8.

7. Baysal V, Yıldırım M, Alan H. Skin diseases most frequently encountered in the Göller region. T Klin J Dermatol 1997; 7: 19-22.

8. Kilkenny M, Merlin K, Young R, et al. The prevalence of common skin conditions in Australian school students: 1. Common, plane and plantar viral warts. Br J Dermatol 1998; 138: 840-5.

9. Theng TS, Goh BK, Chong WS, et al. Viral warts in children seen at a tertiary referral centre. Ann Acad Med Singapore 2004; 33: 53-6.

10. Ozgul N, Tuncer M, Abacioglu M, et al. Estimating prevalence of genital warts in Turkey: survey among KETEM-affiliated gynecologists across Turkey. Asian Pac J Cancer Prev 2011; 12: 2397-400.
11. Kavak A, Parlak AH, Akman R, et al. An evaluation of hepatitis $B, C$ and HIV infections in sexually transmitted diseases. Turkderm 2002; 36: 272-5.

12. Kaymak Y, Yüksel N, Ekşioğlu M. Coincidence of condyloma accuminata with other sexually transmitted diseases. Turkderm 2004; 38: 48-53.

13. Sonnex C, Strauss S, Gray JJ. Detection of human papillomavirus DNA on the fingers of patients with genital warts. Sex Transm Infect 1999; 75: 317-9.

14. Fairley CK, Gay NJ, Forbes A, et al. Hand-genital transmission of genital warts? An analysis of prevalence data. Epidemiol Infect 1995; 115: 169-76.

15. Handley J, Hanks E, Armstrong K, et al. Common association of HPV 2 with anogenital warts in prepubertal children. Pediatr Dermatol 1997; 14: 339-43.

16. Mulhem E, Pinelis S. Treatment of nongenital cutaneous warts. Am Fam Phys 2011; 84: 288-93.

17. Kwok CS, Gibbs S, Bennett C, et al. Topical treatments for cutaneous warts. Cochrane Database Syst Rev 2012; 9: CD001781.

18. Leung L. Recalcitrant nongenital warts. Aust Fam Phys 2011; 40: 40-2.

19. Bacelieri R, Johnson SM. Cutaneous warts: an evidencebased approach to therapy. Am Fam Phys 2005; 72: 647-52.

20. Allen AL, Siegfried EC. The natural history of condyloma in children. J Am Acad Dermatol 1998; 39: 951-5.

21. Bruggink SC, Waagmeester SC, Gussekloo J, et al. Current choices in the treatment of cutaneous warts: a survey among Dutch GP. Fam Pract 2010; 27: 549-53. 